\title{
Texture development during cold and warm rolled samples of AZ31B magnesium alloy
}

\author{
Litzy L. Choquechambi Catorceno1;Luis Flavio Gaspar Herculano1; Hamilton Ferreira Gomes de Abreu 1 \\ IUFC (Federal University of Ceará- Department of Metallurgical Engineering and Materials); Fortaleza, CE, \\ Brazil \\ litzylina@metalmat.ufc.br
}

\begin{abstract}
Magnesium alloy texture can be modified during deformation, recrystallization and phase transformations and can be linked to improve the alloy ductility. In that sense, it was investigated the texture development of a commercial AZ31B magnesium alloy sheet after cold and hot deformation, using $X$ -

ray diffraction. (0001), (1010) e (11 20$)$ and (101 1) pole figures of deformed samples showed that the texture of cold rolled sheets was characterized by a strong (0001) basal fibre texture with a double-peak distribution, where the basal poles were tilted about $\pm 10^{\circ}$ deg away from the normal direction and toward the rolling direction. While the texture of hot-rolled samples was weakened and (0001) basal pole figure was characterized by a single-peak pole. Twins and dynamic recrystallized grains played a vital role during deformation, weakening the intense basal texture.
\end{abstract}

Index Terms-Magnesium alloys, Rolling, Texture

\section{INTRODUCTION}

$\mathrm{N}$ owadays, conventional rolling is still the most traditional techniques used for processing magnesium alloy sheet. However, due to the limited slip systems of the hcp structure at relative low temperatures, magnesium alloys sheets are usually manufactured by hot or warm rolling. The multipasses rolling with small thickness reduction and intermediate annealing is employed to suppress edge cracks and fractures, improving alloy workability $[1,2]$.

Different thermo- mechanical processing and annealing can modify the material texture during deformation, recrystallization and phase transformations. Thus, the mechanical properties of as-rolled sheet are mainly determined by texture and the final grain size, which can be modified by work hardening, recovery, and recrystallization processes [3]. In literature, the preferred orientation is mainly classified into the "deformation texture" and "recrystallization texture". However, a intense texture results in a strong anisotropy and asymmetry in plastic behavior of hexagonal close packed (hcp) magnesium alloys [1,5].

Since, different processing experiences will generate different types of texture; their control is necessary to improve magnesium alloy ductility. The classic texture of conventional rolling is characterized by basal texture, where c-axis <0001> is parallel to the normal direction in most crystals [6].
This basal texture is formed because of $c / a$ ratios of magnesium alloys are approximately equal to the ideal c/a ratio of 1.633. Moreover, after several rolling passes, basal texture gets stronger, and this dramatically damages its deformability [7,2]. This intense basal texture greatly influences further deformation behavior of magnesium alloys due to the low availability of independent slip systems. Moreover, the mechanical anisotropy is further accentuated by the polarity of twins, which are formed under extension stress parallel to the c-axis or contraction stress perpendicular to the c-axis [8].

During deformation processes, if a Mg sheet is compressed along the rolling direction (RD), $\{1012\}$ tension twinning predominates at the early stages of deformation inducing rotation of basal plane by $86^{\circ}$ toward rolling direction, because of the compression axis is perpendicular to the c-axes in most grains. The activation of different deformation mechanisms due to the different angles between the loading direction and the c-axis involves a competition of slip and twinning. By the way, when rolling temperature is increased and a compression load is performed along the normal direction of sheet, non-basal slips and contraction $\{1011\}$ twinning are activated as dominated deformation mechanisms, because of the compression axis is parallel to the c-axes of most grains and both basal slip and $\{10 \overline{1} 2\}$ twinning are little favored at high temperature.

During deformation of an hexagonal structure material, the possible slip systems include three basal $((0001)<a>)$, three prismatic $(\{1010\}<a>)$ and twelve pyramidal $\left(\left\{\begin{array}{lll}101 & 1\end{array}\right\}<a>\right.$ and $(\{11 \overline{2} 2\}<\mathrm{c}+\mathrm{a}>)$. Additionally, six $\{10 \overline{1} 2\}$ extension twinning and $\{1011\}$ contraction twinning systems and a total of twelve double twinning systems are also available [7]. The activation of each deformation mechanism is highly dependent on the texture as well as on the testing temperature and strain rate [8].

Cold rolling textures are dominated by a pronounced $\{0001\}$ fiber texture as a direct consequence of the dominant twinning that leads to a rapid rotation of grain orientations toward $\{0001\}$ and, therewith, readily exhausts the possibility to activate other slip systems or twinning systems at low temperature. 
Extensive twining severely limits the possibility for further forming operations of $\mathrm{Mg}$ sheet [9]. Upon hot deformation, other slip systems (prismatic slip as well as pyramidal $c+a$ slip) are activated much more easily; furthermore, recovery or recrystallization processes are enhanced.

The texture in rolled sheets is possible to describe by means of a series of pole figures constructed by simple X-ray diffraction methods. It can also be represented by $\{h k i l\}<u v$ $t w>$, which means that the $\{h k i l\}$ planes of these grains lie parallel to the sheet plane, whereas their $\langle u v t w\rangle$ direction point is parallel to the rolling direction. Nevertheless, pole figures need to use a crystallite orientation distribution function to describe the orientation frequency in orientation space (three-dimensional-Euler orientation space). The Euler space is defined by three angles (Euler angle) restricted to the region $\{\pi / 2, \pi / 2, \pi / 3\}$. Thus, the ODF is defined as a probability density function of orientation, expressed, in the form of the Euler angles $\varphi 1, \Phi$, and $\varphi 2$.

The ODF of rolled $\mathrm{Mg}$ alloy AZ31B sheet presents the angular range of $\varphi 2$ limited to $60^{\circ}$, because of crystal symmetry. The ODF of hot rolled samples shows a rather weak $\{0001\}$ fiber texture with some scatter toward $\{0112\}\langle 2110\rangle$. Sheet formability is likewise greatly enhanced at elevated temperature [10].

This work aims to investigate the texture development of a commercial AZ31B magnesium alloy sheet after cold and hot deformation in a AZ31 Mg alloy sheet. With that purpose, it was followed the evolution of the microstructure and texture of this material during rolling.

\section{EXPERIMENTAL PROCEDURE.}

The material used in this study was a commercial AZ31 Mg alloy $(\mathrm{Mg}-3 \% \mathrm{Al}-1 \% \mathrm{Zn})$ purchased from Magnesium Elektron in the form of rolled and annealed sheet with $2 \mathrm{~mm}$ in thickness.

The initial microstructure consisted of equiaxed grains (Fig 1), with an average grain size of $13 \mu \mathrm{m}$ and a characteristic strong basal fiber texture (c-axes mostly parallel to normal direction) with a slight spread of the (0001) poles toward rolling direction (Fig 2a).

Small samples with $10 \mathrm{~mm}$ in width and $80 \mathrm{~mm}$ in length were rolled in single-pass with $10 \%$ thickness reduction at room temperature and $30 \%$ of thickness reduction at $250{ }^{\circ} \mathrm{C}$. The roll peripheral speed was $4.5 \mathrm{~m} / \mathrm{s}$. At this speed, the estimated strain rate during cold and warm rolling processes were $2.1 \mathrm{~s}^{-1}$ and $3.5 \mathrm{~s}^{-1}$, respectively.

Microstructure and macrotexture examination of the rolled samples were performed on the rolling surfaces using a combination of characterization techniques: Scanning microscopy and X-ray diffraction. Sample preparation for metallographic analysis consisted on gentle grinding with 600 , 1200 and 2000 grit $\mathrm{SiC}$ papers followed by polishing with 9 $\mu \mathrm{m}, 3 \mu \mathrm{m}$ and $1 \mu \mathrm{m}$ diamond pastes. The polished samples were finally etched with a solution of $10 \mathrm{ml}$ acetic acid, $4.2 \mathrm{~g}$ picric acid, $10 \mathrm{ml}$ water, and $70 \mathrm{ml}$ ethanol.

Measurement of the average grain size was carried out by the linear intercept method on the optical micrographs.
The texture measurements and analyses of texture measurements were conducted using X-ray diffraction in the reflection geometry with $\mathrm{Cr} \mathrm{K} \alpha$ radiation. Experimental $\{10 \overline{1} 0\},\{0002\},\{11 \overline{2} 0\}$ and $\{10 \overline{1} 1\}$ pole figures were collected on a $5^{\circ} \mathrm{X} 5^{\circ}$ grid for sample tilts, $\alpha=0-75^{\circ}$, and azimuthal rotations, $\beta=0-355^{\circ}$. Defocusing corrections were made using experimentally determined defocusing curves from random powder samples. Complete orientation distributions and recalculated full pole figures were determined using the Labtex software.

\section{RESULTS AND DISCUSSION}

\section{a. Microstructure}

The figure 1 illustrates the microstructure of the AZ31 alloy as a received material, which contains granular eutectic precipitates rich in $\mathrm{Al}$ and $\mathrm{Mn}$ and heterogeneously distributed on the solid solution.
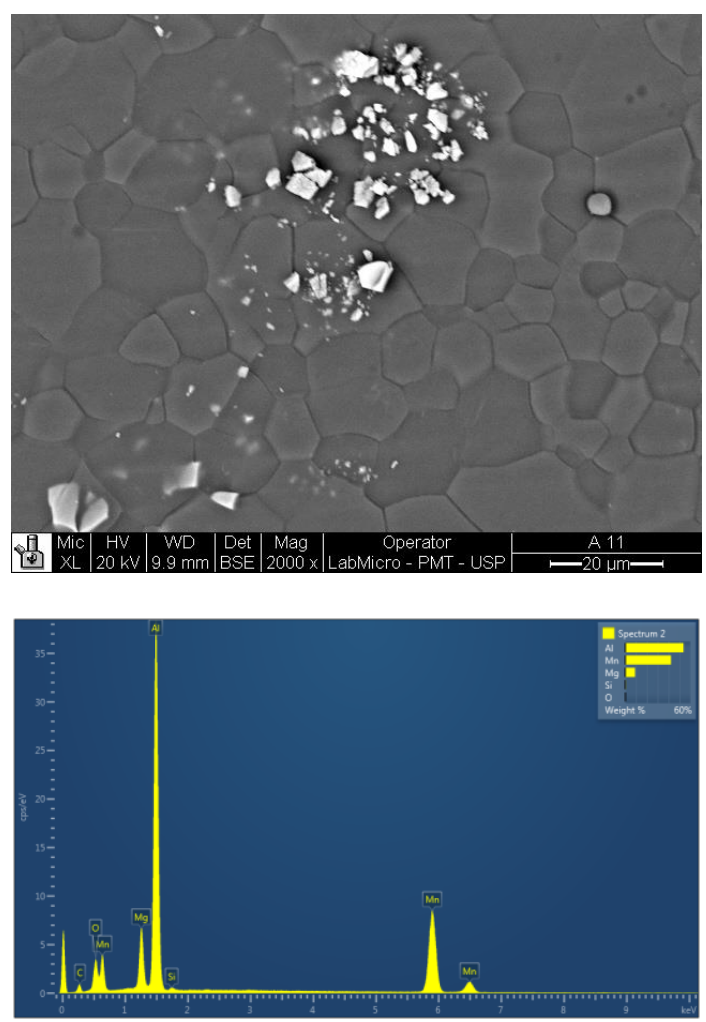

Figure 1. (a) Initial microstructure of as as-received material (b) EDX precipitate spectrum at surface of AZ31Bmagnesium alloy.

After rolling processes, twinning occurs extensively (Fig. 2), indicating most of the strain is accommodated by the twinning. Most of the twins in Figure 2a are considered to be

$\{1012\}$ tensile twinning because it is most easily activated in cold rolling processes and occur preferably on large grains [8]. Thus, the microstructure of the cold-rolled samples was dominated by deformation twinning and shear bands. However, twins and some fine recrystallized grains without twins can be still observed on warm rolled sample (Fig. 2b). 
The dynamic recrystallisation produced a bimodal size distributions formed by finer recrystallized grains and coarser deformed grains.
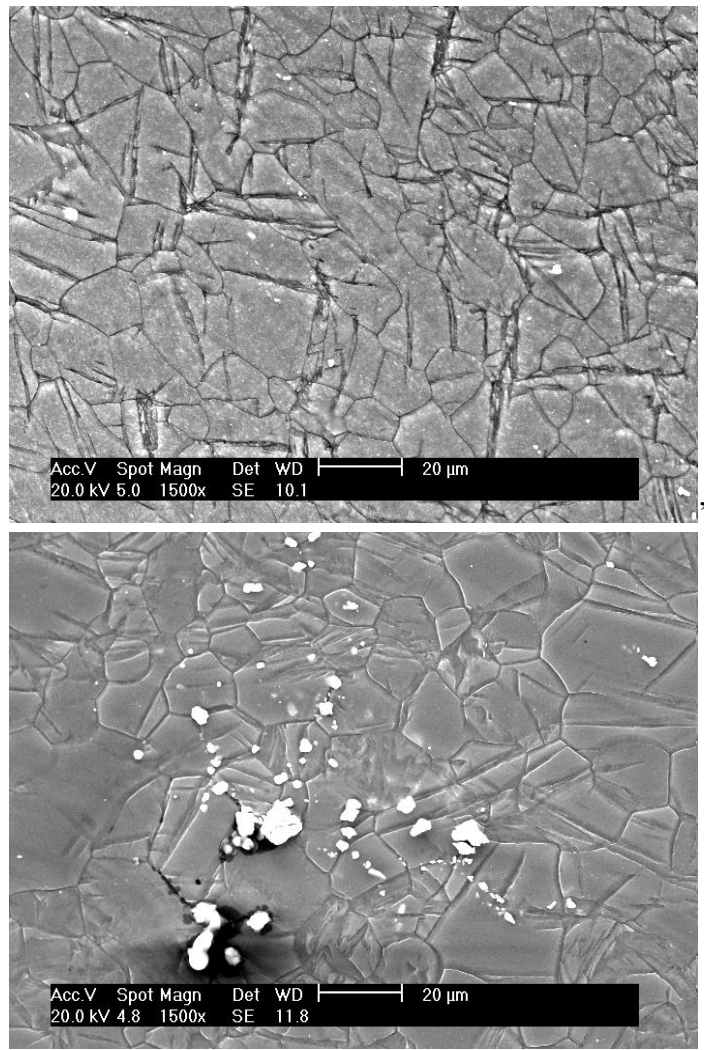

Figure 2. Micrographs obtained from AZ31B rolled specimens: (a) as-cold rolled $25^{\circ} \mathrm{C} / 10 \%$ thickness reduction (b), as- warm rolled, $250^{\circ} \mathrm{C} / 30 \%$ thickness reduction.

\section{b.Texture}

Fig. 1 shows XRD scans of rolled samples and as-received material. Comparing theis X-ray diffraction peaks of cold and warm rolled samples (Fig. 3). It can be noted that the peak's intensities of pyramidal and prismatic peaks are lower that basal and twining peaks. It was a result of low activity at room temperature. Meanwhile, broad and new peaks of non-basal planes were formed at $250^{\circ} \mathrm{C}$ due to twinning and non basal activity. These new peaks was in an angle range of $30-40^{\circ}$ correspond to prism $\{1010\}$, basal $\{0002\}$, and pyramidal $\{1011\}$ planes, and probably the precipitation of crystalline phases also affects the peak's intensities of rolled samples. The strong intensities of basal planes were confirmed on pole figures of rolled samples.

The recalculated pole figures of as received material and rolled samples are shown in the Fig 3 . Where it is possible to see that texture of as-received material has a typical basal texture of a annealed $\mathrm{Mg}$ alloys, formed by a <0001> basal fiber. This texture was developed as a consequence of the occurrence of recrystallization during annealing treatments that follows commonly on industrial rolling processes.

Showing the basal pole figure, it was possible to note that majority of c-axes are aligned with normal direction and spread through the rolling direction. The low intensities of incomplete prismatic and pyramidal pole figures demonstrated that most of prismatic planes are perpendicular to rolling direction in the as-received sheet and almost all basal planes are parallel to rolling direction. By the way, the typical circle where should be the maximum level of intensities of prismatic pole figures was not found because of incomplete measurements. Thus, prismatic pole figures can be unconsidered.

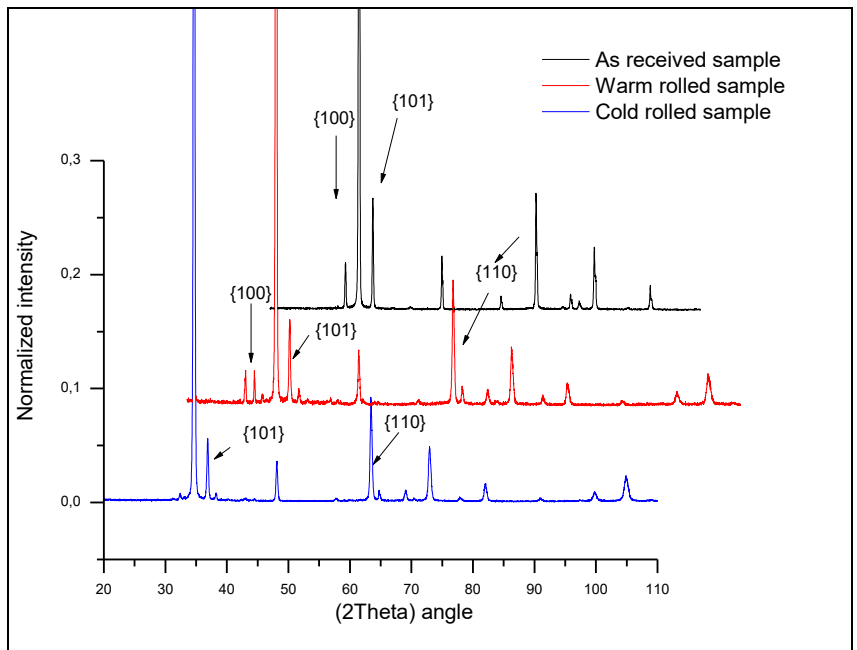

Figure 3. X-ray diffraction scans of rolled samples and asreceived AZ31B magnesium alloy.

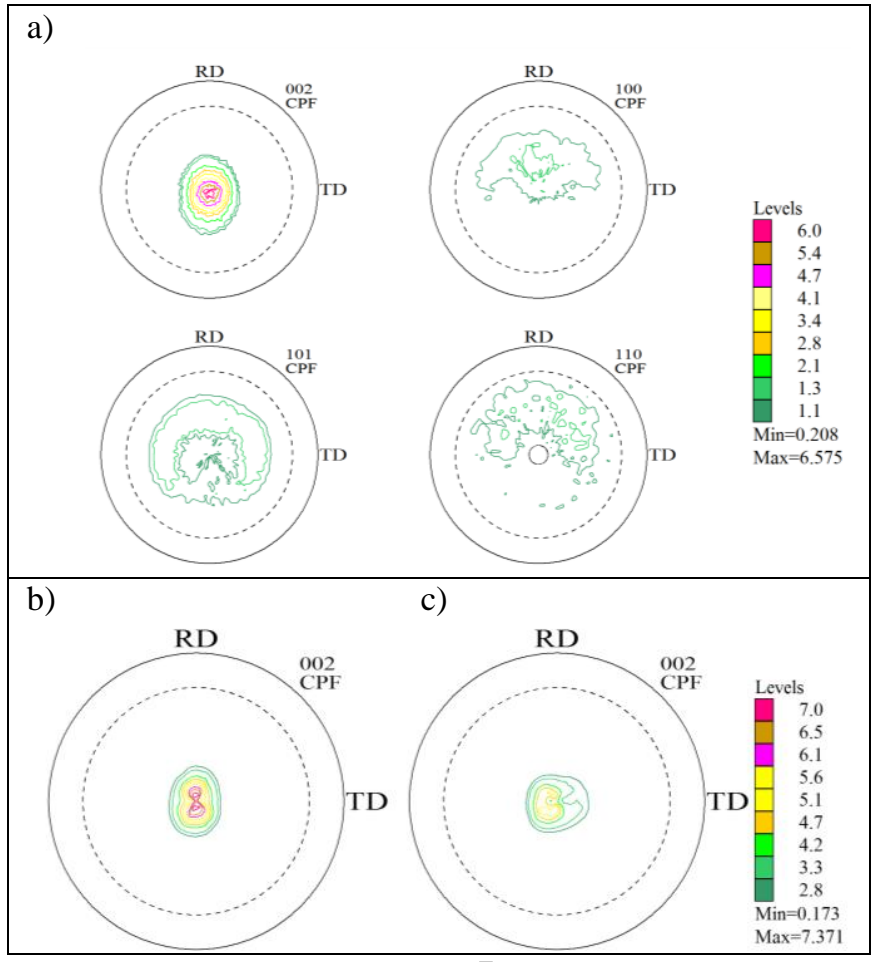

Figure 4 (a) $\{1010\},\{0002\},\{1120\}$ and $\{1011\}$ pole figures illustrating the initial texture (b) texture after cold-rolling with $10 \%$ thickness reduction and (c) texture after warm-rolling with $30 \%$ thickness reduction. 
After cold rolling, basal planes formed a double peak pole figure, in which the position of basal pole tilts \pm 10 to 15 degrees away from the normal direction (ND) and spread towards rolling direction. The transition from the single-peak to double-peak was believed to be caused by twinning and the variation in the shear strain. However, increasing rolling temperature, the peaks returned almost into a single-peak and still spread in the RD

According to intensity values of rolled samples showed on fig. 5 , it can be pointed out that the initial strong basal texture was not weakened on cold rolled sample. On the contrary, the intensity of diffraction peak increased about $10 \%$ more than the initial sample. Meanwhile, in warm rolling sample the initial basal texture was weakened in almost $30 \%$. It was related to dynamic recrystallisation.

The Fig. 5 presents the variation of the texture during rolling processes in terms of ODF and in sections $\phi 2=0^{\circ}$ in which the main texture components of the AZ31B magnesium alloy can be found.

The as-received material showed a fiber texture with the $<1010>$ crystal direction parallel to the original rolling direction. This is a typical texture fiber observed in recrystallized magnesium alloys [12].

During cold rolling, two continuous texture component

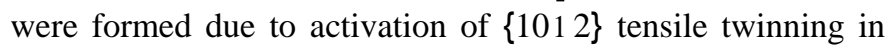
the plastic deformation [4]. The two components of initial microstructure become a big component due to re-oriented basal planes. Although there are no significant texture changes during cold rolling, the fiber component was intensified. Meanwhile, increasing rolling temperature the ODF shows a rather weak $\{0001\}$ fiber texture with some scatter toward $\{01 \overline{1} 2\}\langle 21 \overline{1} 0\rangle$. Thus, sheet formability was likewise greatly enhanced at elevated temperature.

In addition, it is interesting to mention that the maximum intensity of the ODF (texture strength) decreases from 7.3 to 4.7 by increasing the rolling temperature and $30 \%$ of thickness reduction. Meanwhile, the orientations still tend to align along a fiber along to the RD, plus minor intensities of $\{0001\}$ basal planes. The formation of weak texture on warm rolled samples can be explained by the following two factors. First, most of new recrystallized grains appears on twins and acquired a similar orientation of twins, which is characteristic on continuous recrystallization.

As the rolling temperature was $250^{\circ} \mathrm{C}$, dynamic recrystallization takes place, the intensity of the deformation texture decreases and the <0001> fiber texture becomes progressively better defined. Thus, the rotation of grains during twinning offers a possible means to modify the texture by twinning deformation.

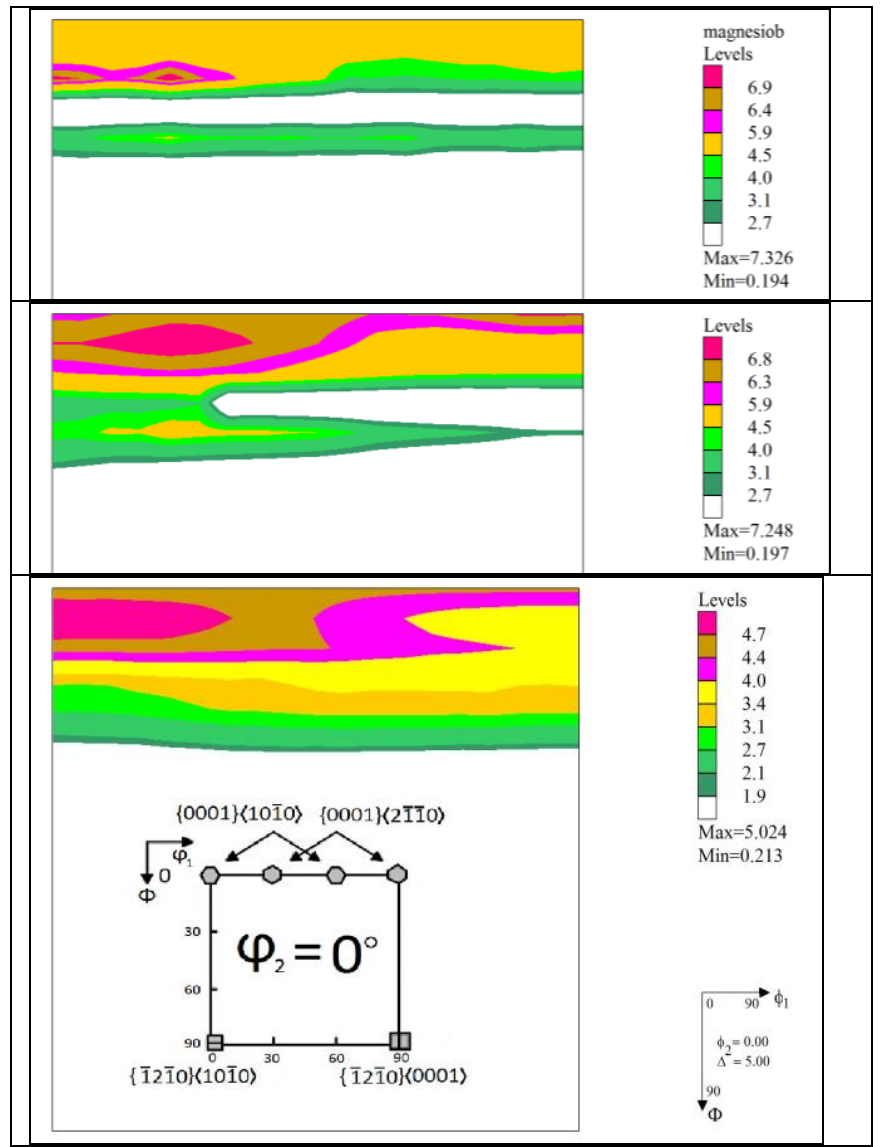

Figure 5. The $\varphi 2=0^{\circ}$ sections of the orientation distribution function (ODF) obtained from: (a) as as-received material (b) as-cold rolled sample $25^{\circ} \mathrm{C} / 10 \%$ thickness reduction (b), aswarm rolled sample, $250^{\circ} \mathrm{C} / 30 \%$ thickness reduction.

\section{Conclusion}

According to the $\{10 \overline{1} 0\},\{0002\},\{11 \overline{2} 0\}$ and $\{10 \overline{1} 1\}$ complete pole figures and ODFs, the major texture of rolled samples can be expressed by a (0001) fiber texture.

Cold rolling processes with low strain rates $(10 \%$ thickness reduction) did not change orientation on the (0002) pole figure significantly.

The intense basal texture initial microstructure was weaken on warm rolling, applying $30 \%$ of thickness under a roll speed of $4.5 \mathrm{~m} / \mathrm{min}$.

On warm rolled sample, a continuous fiber is form by components where the crystal $c$-axis is perpendicular to the rolling direction, which is probably created by activation of non-basal slip systems and twining during hot rolling.

\section{Acknowledgements}

The authors are grateful to the Central Analítica-UFC/CTINFRA/MCTI-SISNANO/Pró-Equipamentos CAPES. (Project code - 2014PP32). 


\section{REFERENCES}

[1] M. Avedesian and H. Baker, ASM Specialty Handbook, "Magnesiumand Magnesium Alloys", ASM International, 1999.

[2] L. Chabbi, W. Lehnert, and R. Kawalla,"Magnesium Alloys and Their Applications," Ed. K. U. Kainer., Wiley-VCH-Verlag, Weinheim, p. 590, 2000

[3] K. Savage, Magnesium and Magnesium Alloys, Casting, Vol 15, ASM Handbook, ASM International, 2008

[4] M. Avedesian and H. Baker, Ed., ASM Specialty Handbook: Magnesium and Magnesium Alloys, ASM International, 1999

[5] Jiang, L. (2008). Effect of twinning on texture and strain hardening in magnesium alloys subjected to different strain paths. PhD thesis, 2008, McGill University, Montreal, Canada.

[6] R.O Kaibyshe.; A.M Galiev, B.K Sokolov,. Effect of grain size on the plastic deformation and dynamic recrystallization of a magnesium alloy. Physics of Metals and Metallography, 78, 2, 1994, pp. 209-217.

[7] M. Bamberger, G. Dehm. Trends in the development of new Mg alloys. Аппи Rev Mater Res, 2008;38:505-533.

[8] T Al-Samman T, X. Li, SG Chowdury. Orientation dependent slip and twinning during compression and tension of strongly textured magnesium AZ31 alloy. Mater Sci Eng A 2010;527:pp3450-3463.

[9] MM, Myshlyaev, HJ McQueen, H Mwembela, E.Konopleva. Tinning, dynamic recovery and recrystallization in hot worked $\mathrm{Mg}-\mathrm{Al}-\mathrm{Zn}$ alloy. Mater Sci Eng A 2002;337:pp. 121-133.

[10] S.R. Agnew, O. Duygulu. Plastic anisotropy and the role of non-basal slip in magnesium alloy AZ31B. International Journal of Plasticity, 21(6): 2005, pp 1161-1193.

[11] D Duly, M C Cheynet, Y Brechet. Morphology and chemical nanoanalysis of discontinuous precipitation in $\mathrm{Mg}-\mathrm{Al}$ alloys:Regular growth [J]. Acta Metall Mater, 1994, 42(1): 3843-3854. 